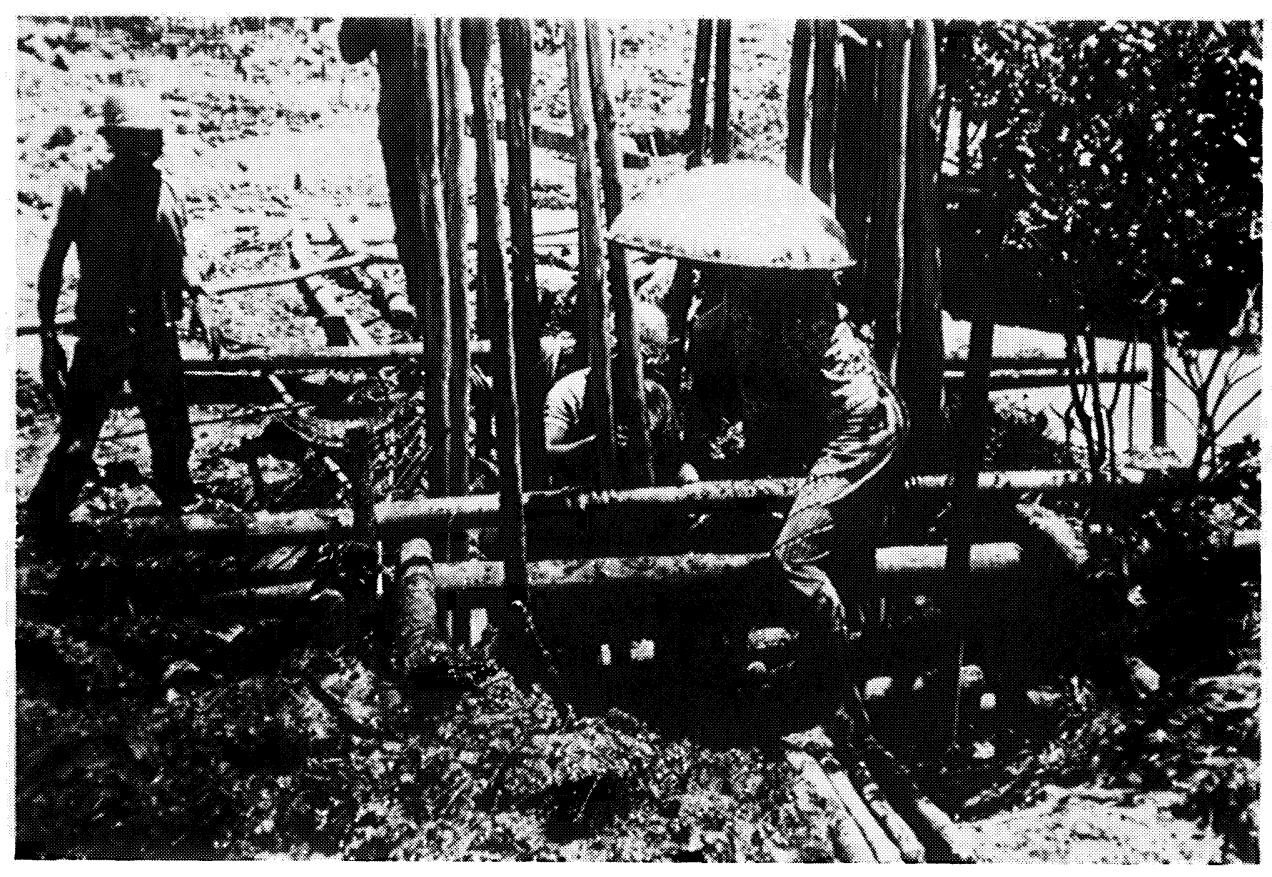

Figure 1. Shaft sinking through a lense of black muck above the diamond bearing gravel. The poles are without bark because it has been used to make baskets to carry excavated material to the surface. 


\title{
PLACER DIAMOND MINING IN KALIMANTAN, INDONESIA
}

\author{
Ronald E. Seavoy*
}

Diamonds, gold, and platinum are recovered by placer mining in the region of Martapura and Pleihari in southeast Kalimantan (Borneo). At the present time, most of the diamonds come from terrace gravels but in the past all three minerals were recovered from river gravels. Platinum is accessory to diamonds and gold, and is never recovered as a primary product.

Al1 three minerals have their sources in the intrusive igneous rocks that form the cores of two parallel mountain ranges: the high and rugged Meratus Mountains and the lower, interior Bobaris Mountains. Most of the placer gold originated from the nearby Bobaris Mountains because a high percentage of the gold particles have ragged textures indicating that they have not moved far from their places of origin. This is confirmed by numerous small placer pits near pleihari where minor water courses along the contact zones of small andesite intrusives (and their downstream extensions) have been excavated to a depth of several meters. The highly laterized material recovered from these excavations has been washed to recover gold, and the bottoms of these pits are paved with quartz rubble that carries minor gold values.

Placer platinum comes from the weathering of the layered ultrabasic rocks that form the cores of the Bobaris and Meratus Mountains. Platinum is accompanied by awaruite ( $\left.\mathrm{FeNi}_{2}-\mathrm{FeNi}_{3}\right)$ which is a natural stainless steel. Awaruite is a byproduct of the serpentinization of peridotite and dunite and is present as minute grains and flakes, but is occasionally found as larger sized particles.

The diamonds come from kimberljte pipes that are associated with the ultrabasic rocks of the Bobaris Mountains. One pipe has been found near the headwaters of the Pamali River, thirty-five kilometers east of Martapura, where a few small diamonds were recovered by washing the laterite soil that partially covered it. ${ }^{1}$ The economic minerals are found within a discontinuous basal layer of coarse gravel that is from thirty centimeters to one meter thick. It was deposited as a series of flat alluvial fans in shallow water along the western edge of the Bobaris Mountains when the sea level was higher than at present and subsequently covered by four to over nine meters of unconsolidated sand, silt, and mud.

The outcrop area of the terrace formation is unoccupied and there are few human or physical barriers to prospecting and rapid exploita-

* The author worked as a consulting exploration geologist in 1970 and 1971 in Indonesia and wishes to thank George C. McBride, chief geologist of Aluminum Company of America who made this study possible.

1. Reinout W. Van Bemmelen, The Geology of Indonesia (The Hague: Nijhoff, 1949), I, pp. 339-41; II, pp. 130, 174, 202-4. 
tion. The gently rolling land surface is either grasslands or secondgrowth forest, both of which have resulted from the use of fire by shifting cultivators. The tenor of the gravels does not appear to be high but a large portion of the recovered diamonds are of gem-quality. There is, however, a major non-economic reason that encourages prospecting and mining. Every miner hopes to find a large diamond that can be sold for a bonanza price. The money received will allow the finder to make a pilgrimage to Mecca--to become a hadji--and in this strongly Muslim"region this will establish him as a man of religious stature and influence who has a valid claim to live a leisurely life at community expense.

Prospecting for payable gravel is done by sinking a shaft approximately one meter square that goes to bedrock. Bedrock is usually a mottled red clay derived from laterized schists. If a prospect shaft finds basal gravel and the gravel contains corundum pebbles ${ }^{2}$ (and perhaps a small diamond) this is considered the best guide for finding concentrations of diamonds because both are heavy minerals and are usually found together. Prospecting is done during the drier months of the year. The local people usually have considerable time available for this activity because there is no population pressure in the region (inland from Martapura and Pleihari, at the edge of the Bobaris Mountains). The people in this area use the technology of wet shifting cultivation which allows them to achieve subsistence with a relatively smal1 expenditure of labor. ${ }^{3}$ On1y a few persons from a village, however, actually engage in diamond mining and it is usually a seasonal activity. When a large diamond is found a rush develops and the area becomes a teeming hive of shaft sinkers. A temporary village forms at the site composed of families or friendly groups from nearby agricultural villages. Each group claims an area and within this area they sink shafts that are spaced five to seven meters apart.

The shaft is of simple but serviceable construction. It has a collar made of logs tied together with split rattan, and around the periphery of the collar poles are driven into the ground as the shaft is deepened. The poles help hold back the water saturated ground until a new tier of log cribbing can be tied into place at the bottom of the shaft (Figure 1). When the shaft reaches bedrock and all of the cribbing is in place the poles are withdrawn and cut up and used to support the ground around the bottom of the shaft until the gravel is recovered. In order to keep the waterlogged muck from flowing into the shaft, after the poles are withdrawn, the space between the log cribbing is filled with thick bunches of grass. The grass is surprisingly effective at sealing the shaft from water inflows (Figure 2) but it is not perfect and a group will often purchase a gasoline powered pump to insure that the working remain unwatered. When al1 of the gravel lying within two or three meters of the shaft has been extracted, as much wood as possible is salvaged for reuse in the next shaft. The unsupported shaft collapses inward and the worked out ground becomes a hummocky surface dotted with pools of water (Figure 3 ).

2. The pebbles are mainly corundum $\left(\mathrm{Al}_{2} \mathrm{O}_{3}\right)$ but they have a substantial content of diaspore $\left(\mathrm{Al}_{2} \mathrm{O}_{3} \cdot \mathrm{H}_{2} \mathrm{O}\right)$. They probably came from a metamorphosed bauxite horizon within the Jurassic and Cretaceous rocks that form the bulk of the Bobaris Mountains.

3. Ronald E. Seavoy, "The Transition to Continuous Rice Cultivation in Kalimantan," Annals of the Association of American Geographers, LXIII (1973), pp. 218-25. 


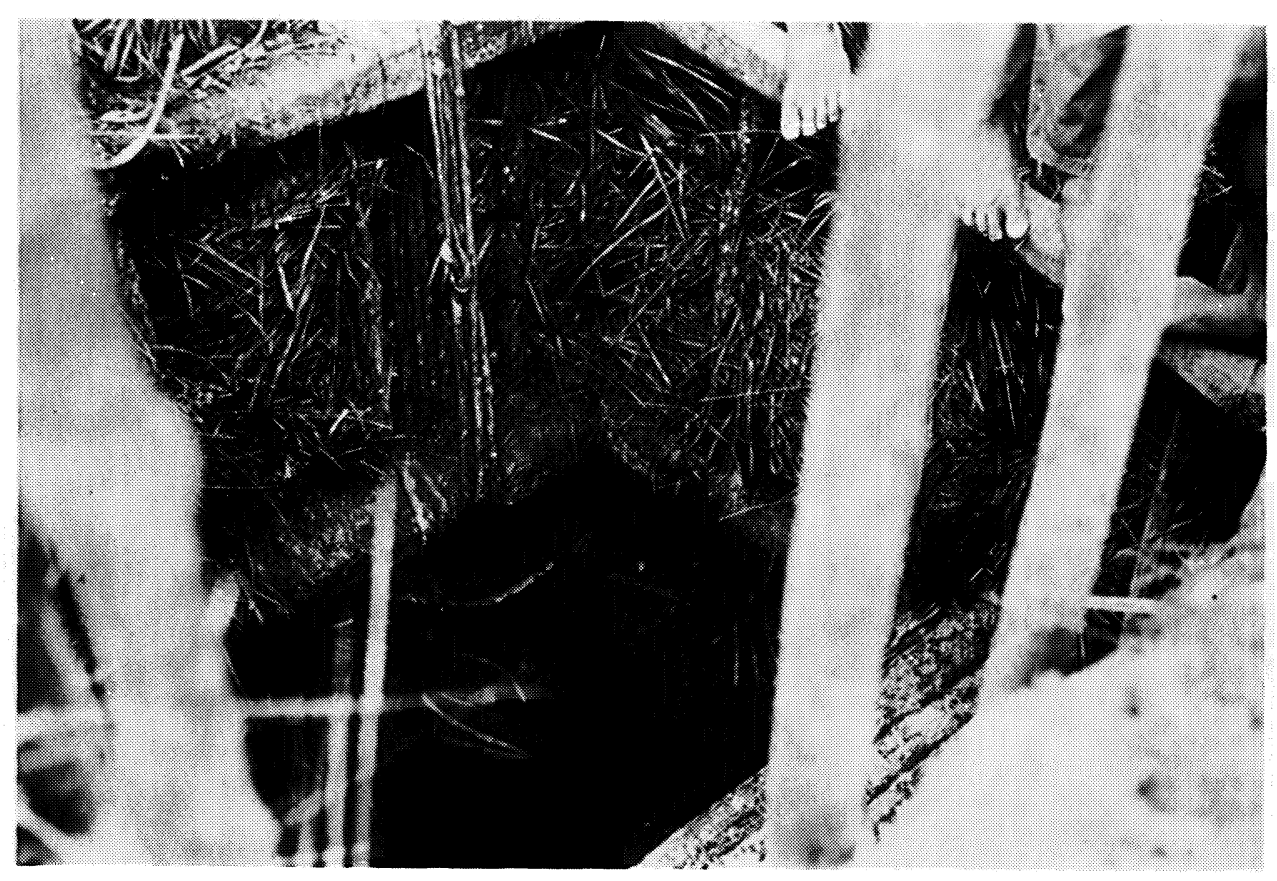

Figure 2. The use of grass to seal the shaft from water and mud inflow. Split ratten is used to hold the lower tiers of wood cribbing in place as the shaft is deepened. Note the small platform in the lower right where a person stands while handing up a basket from the bottom of the shaft.

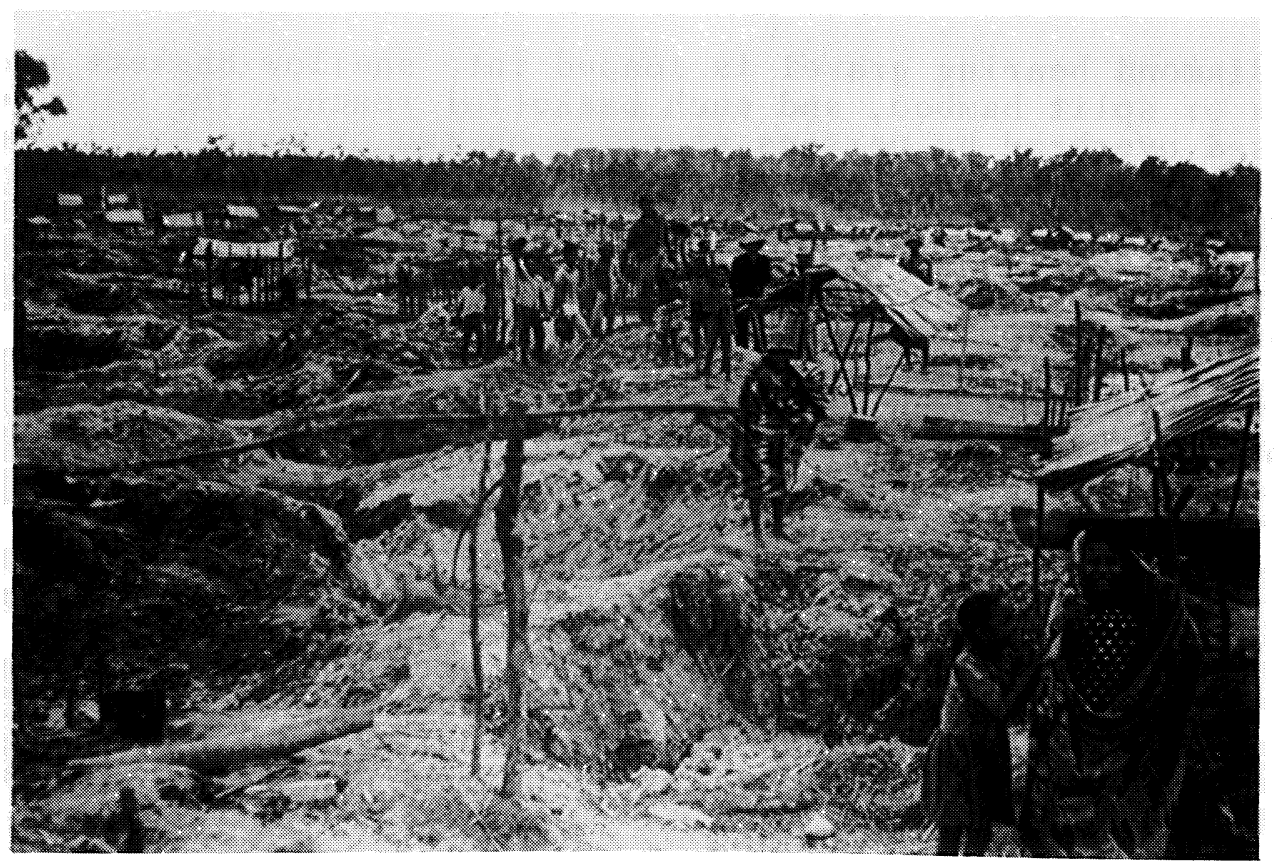

Figure 3. A worked out area where abandoned shafts have caved after most of the wood poles and cribbing has been salvaged for reuse elsewhere. 


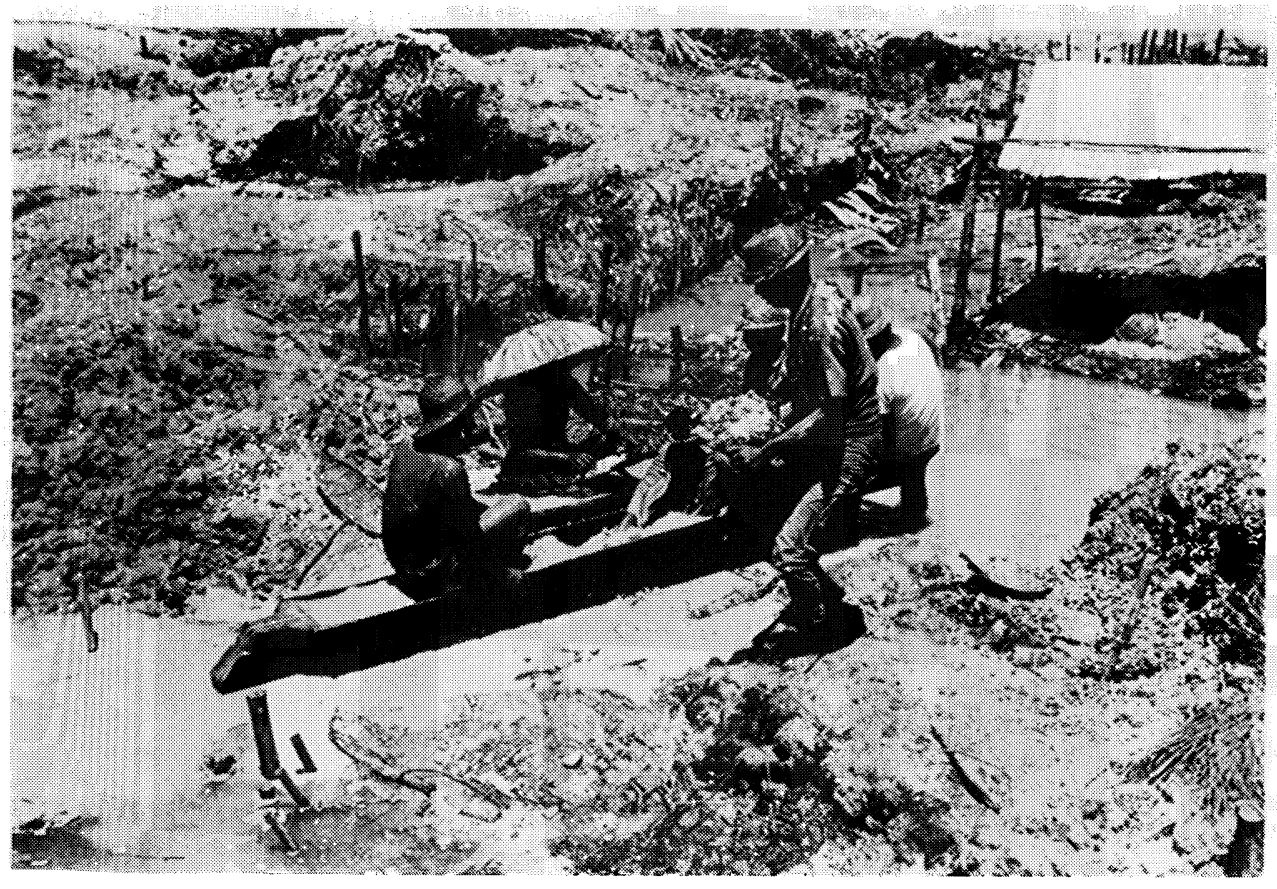

Figure 4. A hollowed log washer where the diamond bearing gravel (in a clay matrix) is emptied when it reaches the surface. The man in the center foreground is about to empty a basket of newly excavated gravel into the washer. The person sitting in the center background (under the hat) is skimming washed gravel and inspecting it before discarding it.

The diamond bearing gravel is loaded into shallow baskets made of woven bark or split bamboo, and each basketful reaches the surface by being passed overhead by persons standing on two or more small platforms inside the shaft. At the surface the gravel is dumped into a hollow log filled with water where it is agitated by pushing and shoving with hands and feet (Figure 4). By continually adding more water and continually agitating the gravel, the clay that binds the sand and gravel particles is put into suspension. When more water is added, the muddy water overflows and the clay is discarded. When all of the particles have been liberated from the clay matrix the larger cobbles are picked out and thrown away. Continued agitation brings the larger particles to the surface where they are skimmed off in coarsely woven bamboo sieves and discarded. The bottom of the $\log$ washer retains a concentrate of fine gravel and sand-sized particles.

These particles are transferred to a large conical pan called a duzang. The dulang is about a meter in diameter and about twenty centimeters deep and is made of light wood so it will float. It is always painted, usually black, in order to reduce wear, but also to present a smooth surface that maximizes the weight differentials between minerals so that the heavier ones quickly sink to the bottom of the cone. It was used by the earliest Indonesian and Chinese miners who first commercially exploited the tin deposits of Bangka and the placer gold fields of northwestern Kalimantan (in the Chinese district), as well 


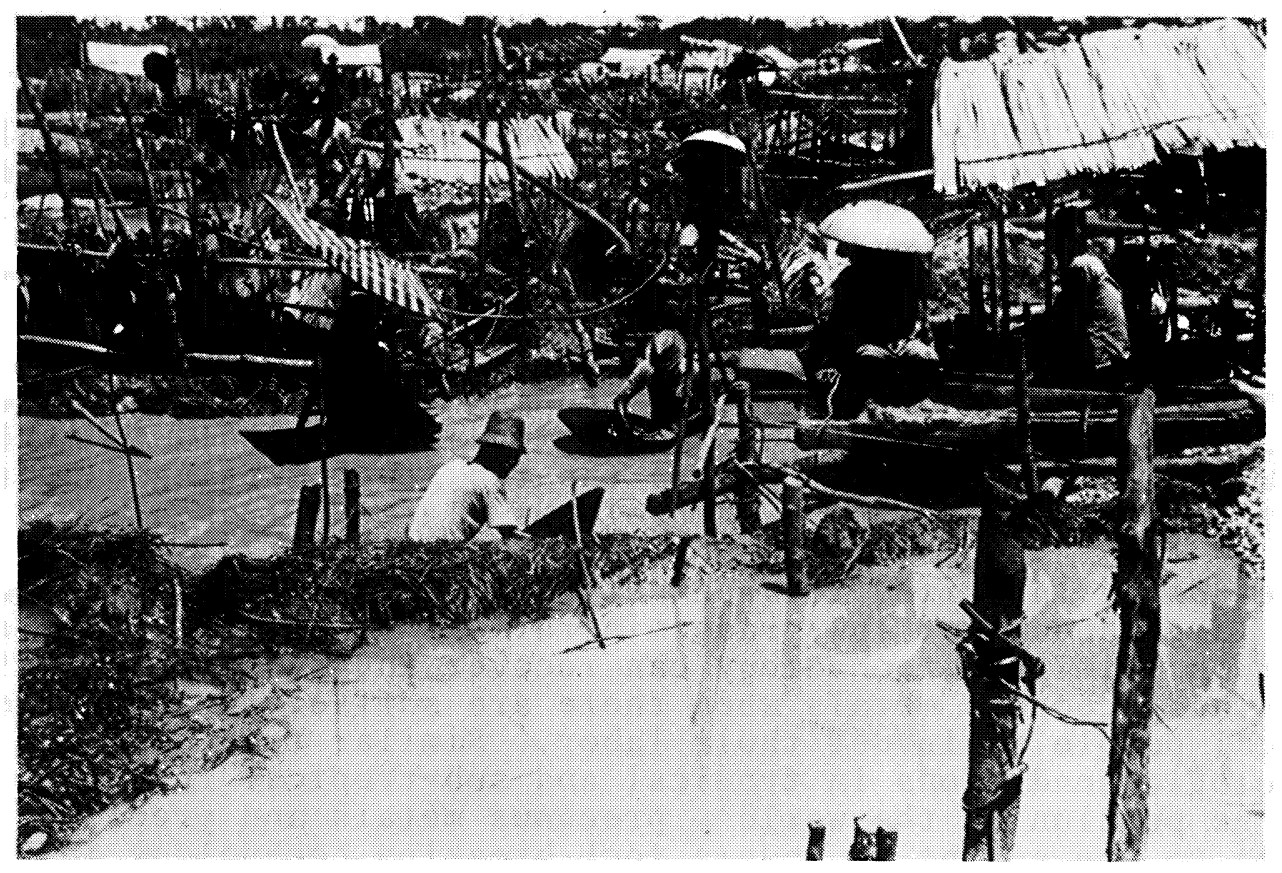

Figure 5. Closely spaced shafts in full operation: mining, log washing, and panning are being done simultaneously. Note the gasoline powered pump in center background.

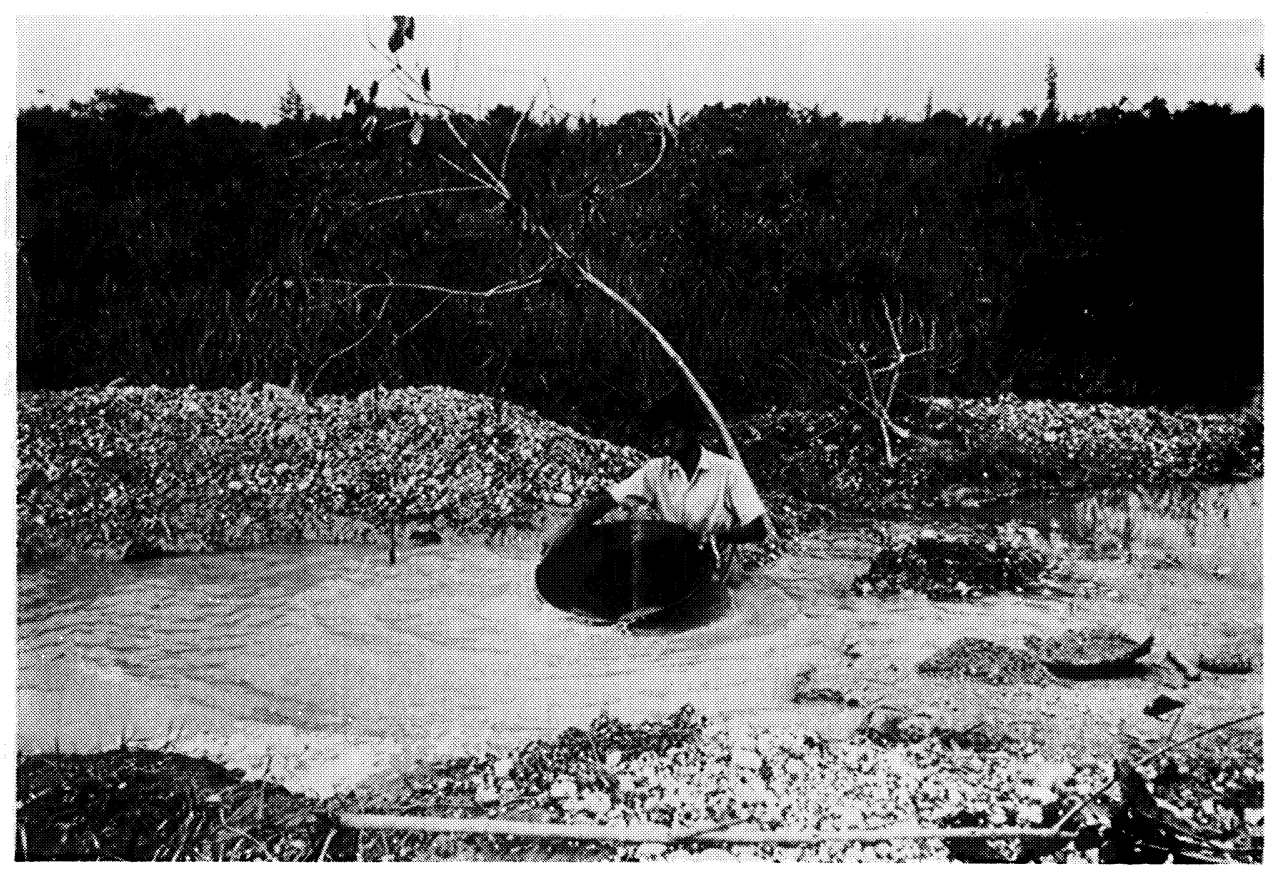

Figure 6. The final stage of panning to recover a heavy mineral concentrate. Note the pile of discarded coarse gravel in the background and the basket of washed sand and fine gravel (from the log washer) in the right foreground. The washed sand and fine gravel is the concentrate that is panned in the dulang. 
as elsewhere in the Malay archipelago. ${ }^{4}$ The man who does the panning stands waist deep in water and continually agitates the concentrate with a circular motion which gradually brings the lighter minerals to the top (Figure 5). Then the pan is tipped on its side so the 1 ighter minerals can be discarded with a few gentle motions (Figure 6). The heavy minerals remain in the bottom of the cone. The water is carefully drained and a search is made for large diamonds. If none are found the concentrate is dumped into a can and taken to the village where the small diamonds are recovered, which are then sold to independent dealers in Martapura or to one of the two jewel cutting factories there. A final panning recovers any gold or platinum present.

In the deeply laterized environment of southeast Kalimantan where there is a large amount of low-grade mineralization in small scattered deposits, this primitive technology can recover substantial quantities of diamonds and precious metals when there are sufficient incentives for the local people to invest their labor. Similar technology under similar geologic conditions in tropical and sub-tropical regions produced a large portion of the world's precious metals and precious stones prior to the advent of modern rock-breaking technology in the middle of the nineteenth century.

4. James C. Jackson, "Mining in 18th Century Bangka: The Pre-European Exploitation of a Tin Island," Pacific Viewpoint, X (1969), pp. 28-29, 42. Bemmelen, Geology of Indonesia, II, P. 107. 